\title{
Body Composition, Blood Pressure, and Lipid Metabolism before and during Long-Term Growth Hormone (GH) Treatment in Children with Short Stature Born Small for Gestational Age Either with or without GH Deficiency*
}

\author{
THEO SAS, PAUL MULDER, AND ANITA HOKKEN-KOELEGA \\ Department of Pediatrics, Division of Endocrinology, Sophia Children's Hospital/Erasmus University \\ (T.S., A.H.-K.), and Institute of Epidemiology and Biostatistics, Erasmus University (P.M.), 3015 GJ \\ Rotterdam, The Netherlands
}

\begin{abstract}
To assess the effects of long-term continuous GH treatment on body composition, blood pressure (BP), and lipid metabolism in children with short stature born small for gestational age (SGA), body mass index (BMI), skinfold thickness measurements, systemic BP measurements, and levels of blood lipids were evaluated in 79 children with a baseline age of 3-11 yr with short stature (height SD-score, $<-1.88$ ) born SGA (birth length SD-score, $<-1.88$ ). Twenty-two of the 79 children were $\mathrm{GH}$ deficient (GHD). All children participated in a randomized, double-blind, dose-response multicenter $\mathrm{GH}$ trial. Fourand 6-yr data were compared between two GH dosage groups (3 vs. $6 \mathrm{IU} / \mathrm{m}^{2}$ body surface/day).

Untreated children with short stature born SGA are lean (mean BMI SD-score, -1.3 ; mean SD-score skinfolds, -0.8 ), have a higher systolic BP (SD-score, 0.7) but normal diastolic BP (SD-score, -0.1), and normal lipids (total cholesterol, $4.7 \mathrm{mmol} / \mathrm{L}$; low-density lipoprotein, $2.9 \mathrm{mmol} / \mathrm{L}$; high-density lipoprotein, $1.3 \mathrm{mmol} / \mathrm{L}$ ) compared with healthy peers. During long-term continuous GH treatment, the BMI normalized without overall changes in sc fat
\end{abstract}

compared with age-matched references, whereas the BP SD-score and the atherogenic index decreased significantly. Although the mean 6-yr increase in height SD-score was significantly higher in the children receiving $\mathrm{GH}$ treatment with $6 \mathrm{IU} / \mathrm{m}^{2} \cdot$ day $(2.7)$ than in those receiving treatment with $3 \mathrm{IU} / \mathrm{m}^{2} \cdot$ day $(2.2)$, no differences in the changes in BMI, skinfold measurements, BP, and lipids were found between the GH dosage groups. The pretreatment SD-scores for BMI, skinfold, and BP, as well as the lipid levels, were not significantly different between GHD and non-GHD children, but after $6 \mathrm{yr}$ of $\mathrm{GH}$ treatment the skinfold SD-score and BP SD-score had decreased significantly more in the GHD than in the non-GHD children.

Our data indicate that GH treatment has at least up to 6 yr positive instead of negative effects on body composition, BP, and lipid metabolism. In view of the reported higher risk of cardiovascular diseases in later life in children born SGA, further research into adulthood remains warranted. (J Clin Endocrinol Metab 85: 3786-3792, 2000)
$S^{\mathrm{H}}$ HORT STATURE IN children born small for gestational age (SGA) is a well known phenomenon. Although postnatal catch-up growth occurs in most of the SGA newborns, about $15 \%$ of these children fail to show catch-up growth, resulting in short adult stature in most of the cases (1-5). The mechanism of the stunted postnatal growth in short children born SGA is poorly understood. It has been previously shown that disturbances in the GH/insulin-like growth factor I axis may account for some of the growth retardation: up to $60 \%$ of the short children born SGA have GH-secretory abnormalities and/or reduced levels of insulin-like growth factors $(6-12)$. Studies have shown that continuous or discontinuous treatment with recombinant human GH in varying dosages accelerates growth significantly in short children born SGA, resulting in catch-up growth to

Received September 21, 1999. Revision received July 5, 2000. Accepted July 5, 2000

Address correspondence and requests for reprints to: T. C. J. Sas, M.D., Sophia Children's Hospital, Department of Pediatrics, Division of Endocrinology, Dr. Molewaterplein 60, 3015 GJ Rotterdam, The Netherlands.

* Supported by Novo Nordisk A/S, Bagsvaerd, Denmark. values within the normal range, followed by growth along their target height percentile $(7,13-21)$

SGA has been associated with increased prevalence of diabetes mellitus type II, hypertension, and hyperlipidemia at a relative young age in later life (22). All three disorders are risk factors of cardiovascular diseases. Concern has been expressed regarding possible adverse effects of long-term GH treatment during childhood. A previous study by our group showed that in short children born SGA either with or without GH deficiency long-term treatment with supraphysiological GH dosages caused a relative insulin resistance (22a), similar to findings in other GH-treated patient groups $(23,24)$. Because relative insulin resistance is associated with the development of diabetes type II, follow-up of these children during long-term GH treatment is required. Data on possible effects of GH treatment on other risk factors for cardiovascular diseases during childhood are very limited in SGA children.

To assess the body composition, blood pressure (BP), and lipid metabolism in children with short stature born SGA before and during long-term continuous GH treatment, the body mass index (BMI), skinfold measurements, systolic and 
diastolic BP, and levels of blood lipids were evaluated in 79 children with short stature born SGA with or without GH deficiency, participating in a randomized, double-blind, dose-response multicenter $\mathrm{GH}$ trial (21). We now report 4- to 6-yr data comparing two GH dosage groups (3 vs. $6 \mathrm{IU} / \mathrm{m}^{2}$ body surface-day).

\section{Subjects and Methods}

\section{Study groups}

Seventy-nine prepubertal short children born SGA were included after meeting the following criteria: 1) birth length SD-score below -1.88 (i.e. less than the third percentile) for gestational age (25); 2) chronological age (CA) between 3 and $11 \mathrm{yr}$ in boys and 3 and $9 \mathrm{yr}$ in girls at the start of the study; 3 ) height SD-score for CA (height SD-score $\mathrm{CA}_{\mathrm{CA}}$ ) below $-1.88(26) ; 4$ ) height velocity SD-score for CA less than or equal to zero (26) to exclude children presenting spontaneous catch-up growth; 5) prepubertal, defined as Tanner breast stage I for girls and testicular volume less than $4 \mathrm{~mL}$ for boys (27); and 6) uncomplicated neonatal period [i.e. without signs of severe asphyxia (defined as an Apgar score below 3 after $5 \mathrm{~min}$ ), without sepsis neonatorum, and without long-term complications of respiratory ventilation]. Exclusion criteria were: endocrine or metabolic disorders, chromosomal disorders, growth failure caused by other disorders or syndromes (emotional deprivation, severe chronic illness, chondrodysplasia), and previous or present use of drugs that could interfere with GH treatment. Patients with Silver-Russell syndrome (SRS), however, were included in this study. GH deficiency was defined as a peak GH secretion less than $10 \mu \mathrm{g} / \mathrm{L}$ during two GH provocation tests or during one provocation test and a $24-\mathrm{h} \mathrm{GH}$ profile. $\mathrm{GH}$ deficiency was not an exclusion criterium.

Four centers in The Netherlands participated in the study. The study was approved by the Ethics Committee of each participating center. Written informed consent was obtained from the parents or custodians of each child.

\section{Study design}

Before GH treatment, 40 of the 79 children underwent a 24-h plasma GH profile, as described previously (6). To stratify for the spontaneous GH secretion during the 24-h GH profile, the total group of 79 children was divided into three groups: "normal profile," "GH-insufficient profile" (area under the curve $<90 \mu \mathrm{g} / \mathrm{L} / 24 \mathrm{~h}$ and mean GH $<2.0 \mu \mathrm{g} / \mathrm{L}$ ), and "no profile performed." After stratification for spontaneous GH secretion during the 24-h GH profile and CA (3.00-5.99, 6.00-8.99, and $9.00-10.99 \mathrm{yr})$, all children were randomly and blindly assigned to either one of two GH dosage groups: group $\mathrm{A}, 3 \mathrm{IU} / \mathrm{m}^{2}$ body surface day; or group $\mathrm{B}, 6 \mathrm{IU} / \mathrm{m}^{2}$ body surface $\cdot$ day $(\approx 0.1$ or $0.2 \mathrm{IU} / \mathrm{kg} \cdot$ day, respectively) $(6,21)$. Biosynthetic GH (recombinant human GH Norditropin; Novo Nordisk A/S, Bagsvaerd, Denmark) was given sc once daily at bedtime with a pen injection system (Nordiject 24; Novo Nordisk A/S). Every 3 months the total GH dose was adjusted to the calculated body surface. The study was kept double-blind by using an equal volume of a reconstituted preparation. Criteria to discontinue the GH treatment were a height velocity below $0.5 \mathrm{~cm}$ over the last 6 months and/or bone age 15 $\mathrm{yr}$ or more for girls and $16.5 \mathrm{yr}$ or more for boys.

Before the start of treatment and every 3 months after the start of GH treatment, all children were seen at their local hospital for a physical examination, including measurements of standing height and weight. Height was expressed as SD-score (21). BMI [weight (kilogram)/height (meter squared)] was expressed as SD-score for sex and CA (21). The thickness of four skinfolds (biceps, triceps, subscapular, and suprailiacal) were measured according to Cameron (28). The measurements of all children were performed by two trained observers (W. de Waal, and later on T.S.) using a Holtain skinfold caliper. Two measurements per visit were made, and the mean was used for the analysis. The sum of the four skinfold measurements were expressed as SD-score using the references for healthy Dutch children (29). To calculate SD-scores, data of the reference population were transformed using the LMS method ( 30 , 31). This method transforms the reference data at each age to a normal distribution. Pubertal stages were assessed by the same two investigators according to Tanner (27), using an orchidometer in boys.
Every 6 months BP was measured. Systolic and diastolic BP was determined with a single Dynamap Critikon 1846SX (Critikon, Inc. Tampa, FL) with the children in a sitting position using a cuff size corresponding to the size of their arm. BP was expressed as SD-score, using age- and sex-specific reference values (age-matched reference values; $\left.\mathrm{BP}_{\mathrm{age}}\right)(32)$. As described previously, a child was considered normotensive if $\mathrm{BP}$ was below the 90th percentile. Because body size is the most important determinant of BP in childhood and adolescence, additionally, we adjusted the pretreatment BP values and those after 6 $\mathrm{yr}$ of GH treatment for height-matched reference values $\left(\mathrm{BP}_{\text {height }}\right)$ (32).

During the first $4 \mathrm{yr}$, once a year, blood samples were collected for the determination of total cholesterol (TC), low-density lipoprotein (LDL) cholesterol, and high-density lipoprotein (HDL) cholesterol. Dutch age-matched reference values were used for TC and HDL cholesterol (33). For the other lipids, our own reference values of healthy children were used (34). The atherogenic index was calculated as the ratio of TC/HDL cholesterol.

\section{Assays}

Lipid analysis was subject to the quality-assessment program of the World Health Organization Regional Lipid Reference Center (Prague, Czech Republic). The TC level was measured using an automated enzymatic method (35) with the CHOD-PAP High Performance reagent kit (Boehringer Mannheim, Mannheim, Germany). HDL and LDL cholesterol were measured by the same method after precipitation. For HDL cholesterol, the phosphotungstate method of Burstein was modified (36). LDL cholesterol precipitation was performed with polyvinylsulfate (Boehringer Mannheim). The overall coefficient of variance for TC, HDL cholesterol, and LDL cholesterol was $2.9 \%, 3.7 \%$, and 5.8\%, respectively.

\section{Statistical analyses}

Because the study remains double-blind until final height, statistical analysis was performed by an independent statistician (P.M.), and, therefore, data are only summarized as mean and SD, unless indicated otherwise. The SD-scores of the pretreatment values and after $6 \mathrm{yr}$ of GH treatment were compared with zero using Student's one-sample $t$ tests. Differences between points in time were tested by paired Student's $t$ tests. Differences between groups were tested using Student's twosample $t$ tests. To compare pretreatment levels or changes during $\mathrm{GH}$ treatment between the GH-deficient (GHD) children and the non-GHD children, multiple linear regression analyses were performed, with adjustment made for baseline covariables. For these analyses, pretreatment age and birth length SD-scores were chosen as baseline covariables along with GH deficiency (yes/no); the changes during treatment were, in addition, adjusted for the GH dose. A $P$ value less than 0.05 was considered significant.

\section{Results}

Table 1 lists the pretreatment clinical data of the 79 children. Both GH dosage groups had similar initial characteristics. Seven children had SRS. Twenty-two children were GHD (Table 2). During the first $5 \mathrm{yr}$, five children dropped out of the study for the following reasons long before reach-

TABLE 1. Mean (SD) pretreatment data for each GH dosage group

\begin{tabular}{lcc}
\hline & $\begin{array}{c}\text { Group A 3 IU } \\
\text { GH/m }{ }^{2} \cdot \text { day } \\
(\mathrm{n}=41)\end{array}$ & $\begin{array}{c}\text { Group B 6 IU } \\
\mathrm{GH} / \mathrm{m}^{2} \cdot \text { day } \\
(\mathrm{n}=38)\end{array}$ \\
\hline Male/female & $31 / 10$ & $21 / 17$ \\
Gestational age (week) & $37.3(3.2)$ & $36.0(4.1)$ \\
Birth length SD score & $-3.6(1.4)$ & $-3.7(1.7)$ \\
Birth weight SD score & $-2.6(1.2)$ & $-2.6(1.0)$ \\
CA (yr) & $7.3(2.1)$ & $7.2(2.4)$ \\
Height SD score & $-3.0(0.7)$ & $-3.1(0.7)$ \\
Target height SD score & $-1.0(0.9)$ & $-0.5(0.9)$ \\
\hline
\end{tabular}


TABLE 2. Mean (SD) pretreatment data for the GHD group as well as for the non-GHD group

\begin{tabular}{lcc}
\hline & $\begin{array}{c}\text { GHD } \\
(\mathrm{n}=22)\end{array}$ & $\begin{array}{c}\text { non-GHD } \\
(\mathrm{n}=57)\end{array}$ \\
\hline GH dosage group A/B & $13 / 9$ & $28 / 29$ \\
Birth length SD score & $-3.1(1.0)$ & $-3.8(1.6)$ \\
Birth weight SD score & $-2.4(1.0)$ & $-2.7(1.1)$ \\
CA (yr) & $8.1(1.6)$ & $7.0(2.3)$ \\
Height SD score & $-3.0(0.6)$ & $-3.1(0.7)$ \\
\hline
\end{tabular}

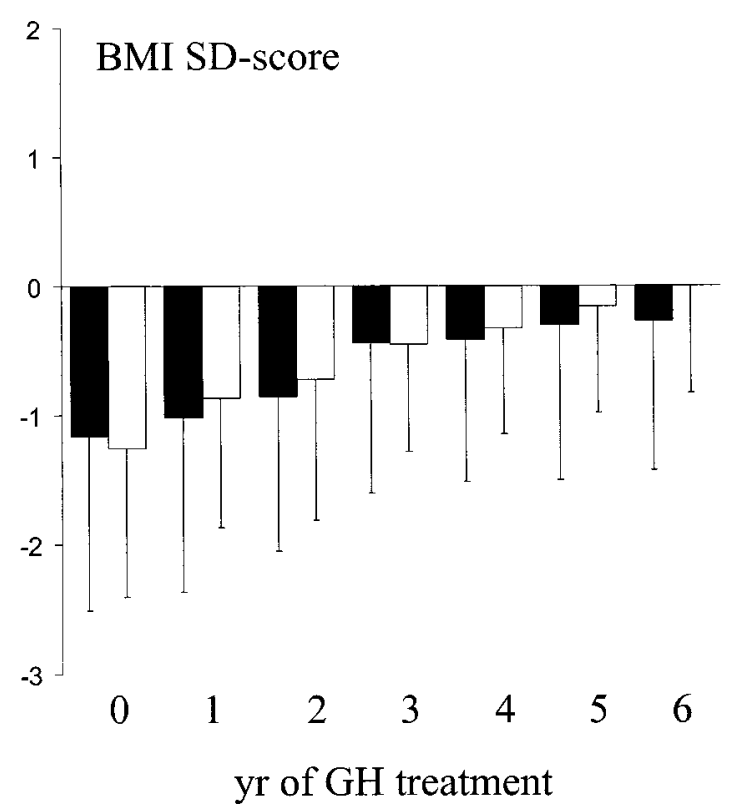

FIG. 1. Mean (SD) BMI SD-score before and during 6 yr of GH treatment for group A (ם) and for group B ( $\square$ ).

ing adult height: treatment of early puberty $(n=1)$, signs of GH insensitivity and no catch-up growth $(\mathrm{n}=1)$, and problems with motivation to inject $\mathrm{GH}(\mathrm{n}=3)$. These five children were lost to follow-up after discontinuation of GH. After $6 \mathrm{yr}$ of GH treatment, in five adolescents GH treatment was discontinued because (near) adult height was reached. Only data obtained during the GH treatment period were included in the analysis. After 6 yr of GH treatment, 17 children were still prepubertal.

\section{Height, BMI, and skinfolds}

The height SD-score increased significantly during GH treatment $(P<0.001)$. The mean $(\mathrm{SD}) 6$-yr increment in height SD-score was significantly higher in group B compared with group A [from - $3.1(0.7)$ to $-0.4(1.1)$ in group B vs. from $-3.0(0.7)$ to $-0.8(0.6)$ in group $\mathrm{A} ; P=0.044]$. The $6-\mathrm{yr}$ increment in height SD-score was not significantly different between the GHD and non-GHD children.

Figure 1 shows the BMI sD-score during 6 yr of GH treatment. The pretreatment mean BMI SD-score of the children was significantly lower than zero. During GH treatment, BMI SD-score increased significantly $(P<0.001)$ to values being not significantly different from zero. The increment in BMI SD-score was not significantly different between the GH dosage groups. Although the pretreatment BMI SD-score in the GHD group was higher than in the non-GHD group, this difference was not statistically significant. The increase in mean (SD) BMI SD-score was not significantly different between the GHD group and the non-GHD group [from -0.8 (1.4) to $-0.2(1.4) v s$. from $-1.4(1.2)$ to $-0.1(0.9)]$.

Figure 2 shows the SD-scores of the sum of the four skinfolds during $6 \mathrm{yr}$ of $\mathrm{GH}$ treatment. In one very obese boys it was not possible to measure the skinfolds appropriately during the study period. The data of all other children were used for this analysis. The pretreatment SD-scores were significantly lower than zero $(P<0.001)$. During the first year, the SD-scores decreased significantly $(P<0.001)$. Thereafter, the mean SD-score increased significantly $(P<0.001)$ to a value being not significantly different from pretreatment values, but still significantly less than zero $(P<0.001)$. No differences in the changes of the SD-scores over time were found between the two GH dosage groups. Although the pretreatment mean SD-score in the GHD group was slightly higher than in the non-GHD group, this difference was not statistically significant. In the GHD group, the mean (sD) skinfold SD-score showed a trend toward lower values after 6 yr of GH treatment [from $-0.5(1.1)$ to $-0.9(0.5)$; this change was significantly different $(P=0.044)$ from the 6-yr change in the non-GHD group (from -1.0 (1.1) to -1.0 (0.9)].

$B P$

Figure 3 shows the SD-scores of $\mathrm{BP}_{\text {age }}$ (using age-matched reference values) before treatment and during treatment, as well as the $\mathrm{BP}_{\text {height }} \mathrm{SD}$-scores (using height-matched references values) before treatment and after $6 \mathrm{yr}$ of treatment. The mean pretreatment systolic $\mathrm{BP}_{\text {age }}$ SD-score was significantly higher than zero, whereas the mean diastolic $\mathrm{BP}_{\text {age }}$ SD-score was significantly lower than zero (Table 3). During 6 yr of $\mathrm{GH}$ treatment, systolic $\mathrm{BP}_{\mathrm{age}}$ decreased significantly to values not significantly different from zero, whereas diastolic $\mathrm{BP}_{\text {age }}$ decreased significantly to values significantly lower than zero. The decrease in the systolic $\mathrm{BP}_{\text {age }} \mathrm{SD}$-score

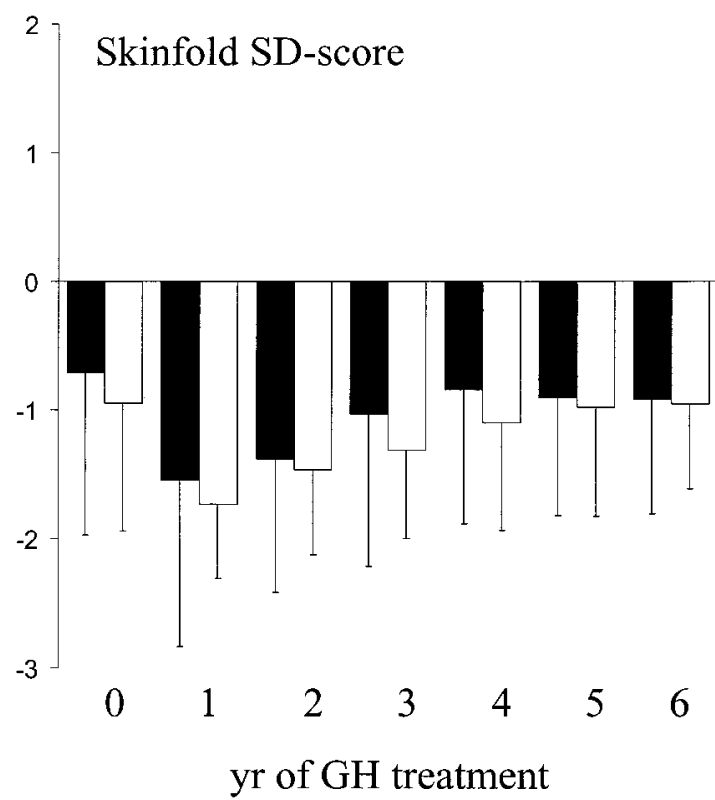

Fig. 2. Mean (SD) skinfold SD-score before and during 6 yr of GH treatment for group A ( $\square)$ and for group B ( $\square)$. 

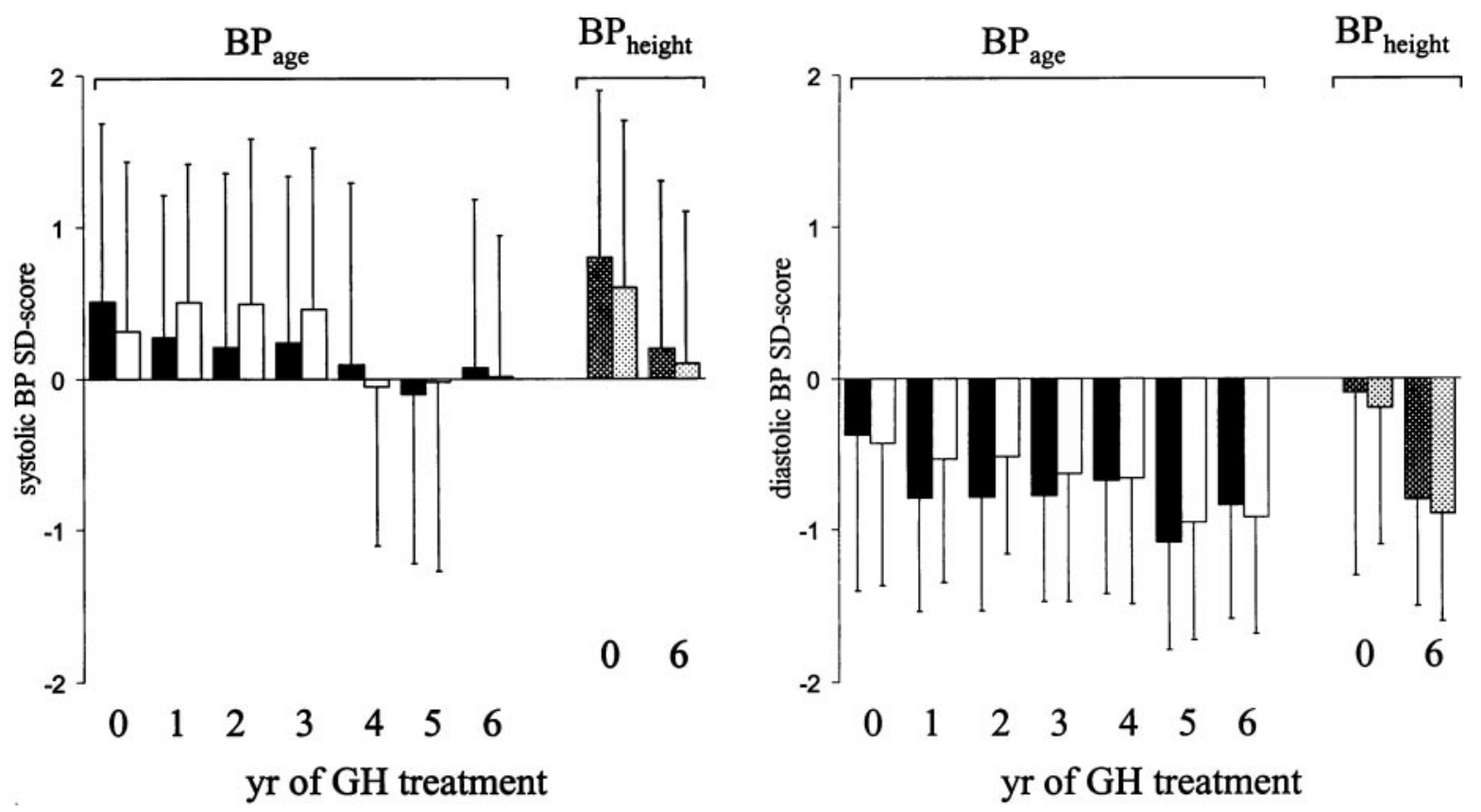

FIG. 3. Mean (SD) systolic BP SD-score (left) and diastolic BP SD-score (right), using age-matched reference values $\left(\mathrm{BP}_{\mathrm{age}}\right)$, before and during $6 \mathrm{yr}$ of GH treatment for group A $(\boldsymbol{\square})$ and for group B $(\square)$. On the right part of each panel is the BP SD-score using height-matched reference values $\left(\mathrm{BP}_{\text {height }}\right)$ before and after 6 yr of $\mathrm{GH}$ treatment.

TABLE 3. Mean (SD) of BP levels before and after $6 \mathrm{yr}$ of GH treatment

\begin{tabular}{|c|c|c|c|c|c|c|}
\hline & \multicolumn{3}{|c|}{ Pretreatment } & \multicolumn{3}{|c|}{ After $6 \mathrm{yr}$} \\
\hline & Group A & Group B & Group A + B & Group A & Group B & Group A + B \\
\hline Systolic BP (mm Hg) & $103(13)$ & $101(13)$ & $102(13)$ & $109(13)$ & $108(12)$ & $109(12)$ \\
\hline Diastolic BP (mm Hg) & $57(10)$ & $56(9)$ & $56(10)$ & $57(7)$ & $56(7)$ & $57(7)$ \\
\hline $\begin{array}{l}\text { Diastolic BP age SD score } \\
\text { no }(\%)>\text { P90 }\end{array}$ & $-0.4(1.0)$ & $-0.4(0.9)$ & $\begin{aligned}-0.4(1.0)^{a} \\
\\
4(5.1 \%)\end{aligned}$ & $-0.8(0.7)$ & $-0.9(0.8)$ & $\begin{array}{l}-0.9(0.8)^{c, d} \\
1(1.4 \%)\end{array}$ \\
\hline $\begin{array}{l}\text { Systolic } \mathrm{BP}_{\text {height }} \text { SD score } \\
\text { no }(\%)>\mathrm{P} 90\end{array}$ & $0.8(1.1)$ & $0.6(1.1)$ & $\begin{array}{c}0.7(1.1)^{c} \\
20(25.3 \%)\end{array}$ & $0.2(1.1)$ & $0.1(1.0)$ & $\begin{array}{l}0.2(1.0)^{e} \\
5(7.2 \%)\end{array}$ \\
\hline
\end{tabular}

$\mathrm{BP}_{\text {age }} \mathrm{SD}$ score, SD score using age-matched reference values; $\mathrm{BP}_{\text {height }} \mathrm{SD}$ score, sD score using height-matched reference values; P90, 90th percentile.

Significantly different from zero: ${ }^{a} P<0.005 ;{ }^{c} P<0.001$.

Significantly different from pretreatment values: ${ }^{b} P<0.05 ;{ }^{d} P<0.001 ;{ }^{e} P<0.01$.

was particularly seen during the last $3 \mathrm{yr}$ of the study period. The mean pretreatment systolic $\mathrm{BP}_{\text {height }}$ SD-score was even higher than that of systolic $\mathrm{BP}_{\text {age, }}$ whereas, in contrast to the diastolic $\mathrm{BP}_{\text {age }} \mathrm{SD}$-score, the mean diastolic $\mathrm{BP}_{\text {height }} \mathrm{SD}$-score was not significantly different from zero (Table 3). Consequently, before treatment, about a quarter of the children had a systolic BP above the 90th percentile using height-matched reference values. After $6 \mathrm{yr}$ of GH treatment, a similar change was found for the SD-scores of $\mathrm{BP}_{\text {height }}$ as for the $\mathrm{BP}_{\text {age }}$ SDscores. No differences in the BP changes were found between $\mathrm{GH}$ dosage groups. The pretreatment $\mathrm{BP}_{\text {age }} \mathrm{SD}$-score was not significantly different between the GHD and non-GHD children. The changes in the systolic BP SD-score as well as in the diastolic BP SD-score during GH treatment were significantly higher in the GHD group than in the non-GHD group: mean (sD) systolic $\mathrm{BP}_{\text {age }}$ SD-score from $0.8(0.8)$ to 0.0 (1.1) vs. 0.3
(1.2) to $0.1(1.0), P=0.037$; diastolic $\mathrm{BP}_{\text {age }} \mathrm{SD}$-score from -0.2 $(0.9)$ to -1.0 (0.8) vs. from -0.5 (1.0) to $-0.8(0.7), P=0.014$.

\section{Lipids}

Figure 4 shows the levels of TC, LDL cholesterol, and HDL cholesterol. Table 4 shows the lipid levels before and after 4 yr of GH treatment. The pretreatment mean levels of the lipid profiles were normal. Three children (3.8\%) had TC more than $6 \mathrm{mmol} / \mathrm{L}$, seven children $(8.9 \%)$ had LDL cholesterol more than $3.7 \mathrm{mmol} / \mathrm{L}$, and two children $(2.6 \%)$ had HDL cholesterol less than $0.9 \mathrm{mmol} / \mathrm{L}$. After $4 \mathrm{yr}$ of $\mathrm{GH}$ treatment, none of the children had an abnormal TC, whereas three $(4.1 \%)$ of the children had LDL cholesterol more than 3.7 $\mathrm{mmol} / \mathrm{L}$ and three children (3.8\%) had HDL cholesterol less than $0.9 \mathrm{mmol} / \mathrm{L}$. During $4 \mathrm{yr}$ of $\mathrm{GH}$ treatment, TC, LDL 


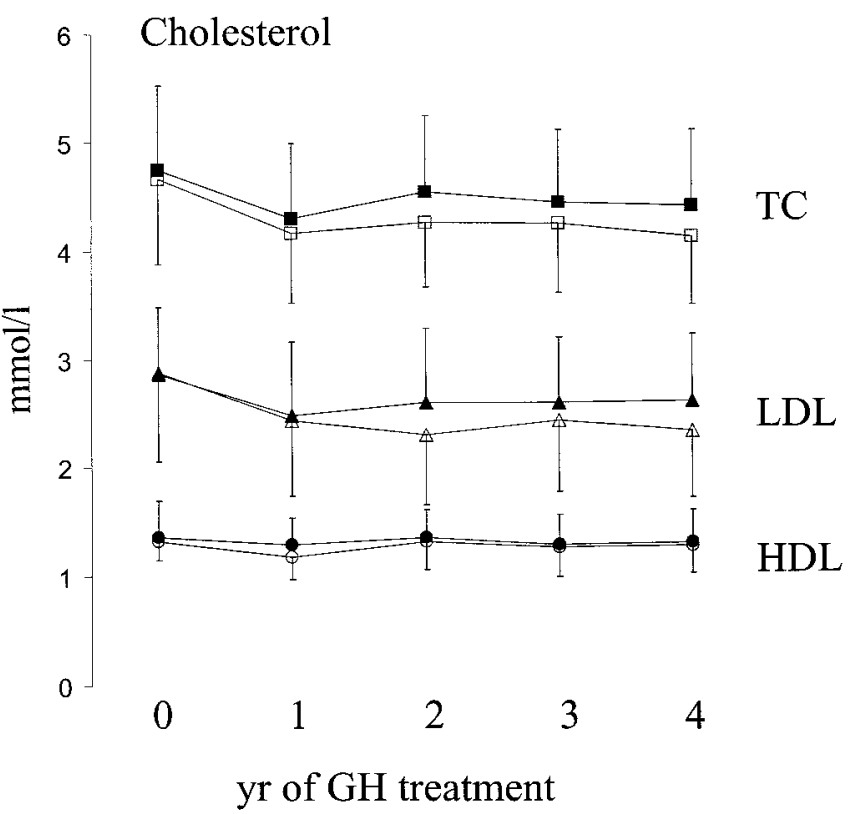

FIG. 4. Mean (SD) levels of TC (squares), LDL cholesterol (triangles), and HDL cholesterol (circles) before and during $4 \mathrm{yr}$ of GH treatment for group A (filled symbols) and for group B (open symbols).

cholesterol, and the atherogenic index significantly decreased, whereas HDL cholesterol remained unchanged. The changes in lipid levels were not significantly different between the GH dosage groups. In the GHD group, similar results were found as in the non-GHD group: mean (SD) TC from 4.9 (0.9) to $4.5(0.7) \mathrm{mmol} / \mathrm{L}$, LDL cholesterol from 2.9 (0.8) to $2.6(0.7) \mathrm{mmol} / \mathrm{L}$, and HDL cholesterol from $1.4(0.3)$ to $1.4(0.3) \mathrm{mmol} / \mathrm{L} v s$. TC from $4.6(0.7)$ to $4.2(0.6) \mathrm{mmol} / \mathrm{L}$, LDL cholesterol from $2.9(0.7)$ to $2.4(0.6) \mathrm{mmol} / \mathrm{L}$, and HDL cholesterol from $1.3(0.3)$ to $1.3(0.3) \mathrm{mmol} / \mathrm{L}$.

\section{Subgroups}

Children who remained prepubertal throughout the whole study period showed similar patterns in BMI, skinfold thicknesses, BP, and lipids as the whole study group. The data of the children with SRS were also comparable with the total study group. During GH treatment similar patterns of the results were found in boys as in girls (data not shown).

\section{Discussion}

Our study is the first demonstrating data on body composition and BP, as well as lipids, before and during longterm continuous GH treatment in children with short stature born SGA either with or without GH deficiency. In short children born SGA, height, BMI, and the thickness of the skinfolds were lower than age-matched controls. Whereas the height SD-score and BMI SD-score increased significantly during 6 yr of GH treatment, the skinfolds measurements showed an initial decrease in SD-score, followed by an increase to pretreatment levels, thereby still remaining significantly lower than age-matched reference values. The changes in body composition during GH treatment were not significantly different between the GH dosage groups. Thus, short children born SGA have a low weight compared to height and have a relatively low body fat percentage. During 6 yr of GH treatment, the catch-up in height was accompanied by an increase in body weight for height, without an overall change in body fat percentage compared with healthy controls. Before treatment, $28 \%$ of the patients were considered GHD. A previous study describing the 5-yr data on height showed that the growth response on long-term $\mathrm{GH}$ treatment was comparable between the GHD children and the non-GHD children (21). In the present study, we found that the pretreatment BMI SD-score and the skinfold SD-score of the GHD children were not significantly different from the non-GHD children. During GH treatment, a similar change of the BMI SD-score was found for the GHD children as for the non-GHD children, whereas the small decrease in skinfold SD-score in the GHD children over 6 yr was significantly greater than in the non-GHD group.

Our data are comparable with the results of the fat and muscle measurements using magnetic resonance imaging described by Leger et al. (37). They reported an increase in muscle tissue cross-sectional area in 14 prepubertal short children born SGA without GH deficiency during 3 yr of GH treatment with $0.2 \mathrm{IU} / \mathrm{kg} \cdot$ day $\left(\approx 6 \mathrm{IU} / \mathrm{m}^{2} \cdot\right.$ day $)$. In addition, the adipose tissue cross-sectional area showed an initial decrease during the first year of treatment, followed by an increase in the second and third years to values similar as to a control group of seven healthy children (37).

Several earlier reports have demonstrated the negative relationship between birth weight and BP in childhood as well as in adulthood $(22,38-40)$. Therefore, the SGA children may be more at risk of hypertension in later life than their healthy peers. To optimize GH treatment in children with short stature born SGA, supraphysiological GH doses are given for a long period during childhood. Because in adults GH hypersecretion in acromegaly is associated with an increased incidence of hypertension (41), concern has been expressed regarding possible negative effects of long-term GH treatment in these children. We showed that pretreatment systolic BP was significantly higher than age-matched as well as height-matched reference data, whereas pretreatment diastolic BP was significantly lower compared with age-matched reference data, but not significantly different compared with height-matched reference data. During GH treatment, the SD-scores of systolic and diastolic BP decreased significantly. After 6 yr, systolic BP was not different from controls anymore, whereas diastolic BP was even lower than healthy age-matched and height-matched controls. The changes in the BP SD-scores were not significantly different between the GH dosage groups. The GHD children showed a significantly greater decrease in $\mathrm{BP}$ SD-score than the nonGHD children, resulting in similar BP SD-scores after 6 yr in these two groups. Barton et al. (42) described that in contrast to adult subjects, treatment with a high dose of GH in short children is not associated with activation of the renin-angiotensin-aldosterone system (42). This suggests that it is unlikely that GH treatment in childhood is associated with the increased risk of hypertension seen in adults with GH hypersecretion. Our long-term data support these findings by showing even a decrease in the $\mathrm{BP}$ SD-scores during treatment with $\mathrm{GH}$ in dosage up to $6 \mathrm{IU} / \mathrm{m}^{2}$.day.

$\mathrm{GH}$ deficiency is associated with dyslipidemia $(43,44)$. 
TABLE 4. Mean (SD) of the lipid values before and after $4 \mathrm{yr}$ of GH treatment

\begin{tabular}{|c|c|c|c|c|c|c|c|}
\hline & \multicolumn{3}{|c|}{ Pretreatment } & \multicolumn{3}{|c|}{ After 4 years } & \multirow{2}{*}{$\begin{array}{l}\text { Reference } \\
\text { values }\end{array}$} \\
\hline & Group A & Group B & Group A + B & Group A & Group B & Group A + B & \\
\hline Total cholesterol $(\mathrm{mmol} / \mathrm{L})$ & $4.7(0.8)$ & $4.7(0.8)$ & $4.7(0.8)$ & $4.4(0.7)$ & $4.1(6.2)$ & $4.3(0.7)^{a}$ & $3.2-6.0$ \\
\hline $\mathrm{LDL}(\mathrm{mmol} / \mathrm{L})$ & $2.9(0.6)$ & $2.9(0.8)$ & $2.9(0.7)$ & $2.6(0.6)$ & $2.3(0.6)$ & $2.5(0.6)^{a}$ & $1.3-3.7$ \\
\hline HDL (mmol/L) & $1.4(0.3)$ & $1.3(0.2)$ & $1.3(0.3)$ & $1.3(0.3)$ & $1.3(0.2)$ & $1.3(0.3)$ & $0.9-1.6$ \\
\hline Atherogenic index & $3.6(0.8)$ & $3.6(0.8)$ & $3.6(0.8)$ & $3.5(0.8)$ & $3.3(0.7)$ & $3.4(0.8)^{b}$ & \\
\hline
\end{tabular}

Significantly different from pretreatment values: ${ }^{a} P<0.001 ;{ }^{b} P=0.018$.

Barker et al. (22) demonstrated the negative correlation between birth weight and syndrome $X$ (hypertension, diabetes mellitus type II, and hyperlipidemia) in adult men. Consequently, the children of our study seem to be at risk of problems with lipid metabolism in later life. In the present study, we showed that children with short stature born SGA had normal mean pretreatment lipid values. In addition, no differences in lipids were found between the GHD and the non-GHD SGA children. No previously published data are available about the effects of GH treatment on lipids in children with short stature born SGA, whereas the effects of GH treatment in GHD children are inconsistent. Some studies showed no changes in TC and HDL cholesterol during shortterm GH treatment (45), whereas others found a decrease in TC (46) or an increase in HDL cholesterol (47). In the present study, TC, LDL cholesterol, and the atherogenic index decreased significantly during the first year of GH treatment and remained stable thereafter, whereas HDL cholesterol did not change during GH treatment. In a study evaluating the effects of lipid profiles, the atherogenic index was the most efficient predictor of coronary heart diseases in adults (48). We found similar patterns in the GHD children as in the non-GHD children. Similar changes in lipids were seen in the children who remained prepubertal throughout the entire study period as in the total study group. Thus, the start of puberty during treatment cannot explain the changes in the lipid profiles. In healthy children, no age-related change in TC was observed between 5 and 10 yr of age, but TC decreased between 10 and 16 yr in boys, as well as in girls (33). During the first year of GH treatment most children were younger then 10 year of age. It is, therefore, likely that the changes, particularly seen in the first year of treatment, are not age related but due to GH. Thus, GH treatment seems to have a beneficial effect on lipid metabolism in children with short stature born SGA.

Although the increment in height SD-score was higher in the children receiving $\mathrm{GH}$ treatment with $6 \mathrm{IU} / \mathrm{m}^{2}$-day compared with $3 \mathrm{IU} / \mathrm{m}^{2} \cdot$ day, no differences were found between the two GH dosages groups regarding the change in BMI, skinfold thicknesses, BP, and lipids. To assess whether the changes in body composition, BP, and lipids during GH treatment were dependent on the baseline endogenous GH status, we divided the total group in GHD and non-GHD children by using the Dutch definition of GH deficiency (peak GH secretion, $<10 \mu \mathrm{g} / \mathrm{L}$ during two GH tests). Compared to North America, our definition is quite liberal. Before GH treatment, BMI, skinfold, and BP SD-scores, as well as the lipid levels, were not significantly different between GHD and non-GHD children. During GH treatment, however, the changes in the skinfold SD-score and BP SD-score were slightly, but significantly, greater in the GHD than in the non-GHD children, resulting in similar values after $6 \mathrm{yr}$ of $\mathrm{GH}$ treatment in both groups.

In our opinion, it is reassuring that our data show that long-term GH treatment does not seem to have a negative effect on BP and lipids. However, follow-up of these children into adolescence is warranted because problems might arise later in life. Another reason for long-term follow-up is the evaluation of metabolic changes and changes in body composition after discontinuation of GH treatment, as described previously in young GHD adults (49).

In conclusion, untreated children with short stature born SGA either with or without GH deficiency are lean and have a higher systolic BP, but normal diastolic BP and normal lipids compared with healthy peers. During long-term continuous $\mathrm{GH}$ treatment with 3 or $6 \mathrm{IU} / \mathrm{m}^{2} \cdot$ day, the BMI normalized without overall changes in sc fat compared with healthy controls, whereas the BP SD-score and the atherogenic index decreased significantly, indicating that GH treatment has at least up to $6 \mathrm{yr}$ of positive instead of negative effects on these parameters. In view of the reported higher risk of cardiovascular diseases in later life in children born SGA, additional research into adulthood remains warranted.

\section{Acknowledgments}

Mrs. Janneke van Nieuwkasteele, research nurse, is gratefully acknowledged for her assistance.

\section{References}

1. Albertsson-Wikland K, Karlberg J. 1994 Natural growth in children born small for gestational age with and without catch-up growth. Acta Paediatr Scand. 399(Suppl):64-70.

2. Hokken-Koelega ACS, de Ridder MAJ, van Lemmen RJ, den Hartog $H$, de Muinck Keizer-Schrama SMPF, Drop SLS. 1995 Children born small for gestational age: do they catch-up? Pediatr Res. 38:267-271.

3. Job JC, Rolland A. 1986 Histoire naturelle des retards de croissance à début intra-utérin. Arch Fr Pediatr. 43:301-306.

4. Chaussain JL, Colle M, Ducret JP. 1994 Adult height in children with prepubertal short stature secondary to intra uterine growth retardation. Acta Paediatr Scand. 399(Suppl):72-73.

5. Karlberg J, Albertsson-Wikland K. 1995 Growth in full-term small-forgestational-age infants: from birth to final height. Pediatr Res. 38:733-739.

6. de Waal WJ, Hokken-Koelega ACS, Stijnen T, de Muinck Keizer-Schrama SMPF, Drop SLS. 1994 Endogenous and stimulated GH secretion, urinary GH excretion, and plasma IGF-I and IGF-II levels in prepubertal children with short stature after intrauterine growth retardation. Clin Endocrinol. 41:621-630

7. Albertsson-Wikland K. 1989 Growth hormone secretion and growth hormone treatment in children with intrauterine growth retardation. Acta Paediatr Scand. 349(Suppl):35-41.

8. Rochiccioli P, Tauber M, Moisan V, Pinkowski C. 1989 Investigation of growth hormone secretion in patients with intrauterine growth retardation. Acta Paediatr Scand. 349(Suppl):42-46.

9. Stanhope R, Ackland F, Hamill G, Clayton J, Jones J, Preece MA. 1989 Physiological growth hormone secretion and response to growth hormone treatment in children with short stature and intra-uterine growth retardation. Acta Paediatr Scand. 349(Suppl):47-52. 
10. Boguszewski M, Rosberg S, Albertsson-Wikland K. 1995 Spontaneous 24hour growth hormone profiles in prepubertal small for gestational children. J Clin Endocrinol Metab. 80:2599-2606.

11. Boguszewski M, Jansson C, Rosberg S, Albertsson-Wikland K. 1996 Changes in serum insulin-like growth factor I (IGF-I) and IGF-binding protein-3 levels during growth hormone treatment in prepubertal short children born small for gestational age. J Clin Endocrinol Metab. 81:3902-3908.

12. Boguszewski CL, Jansson C, Boguszewski M, Rosberg S, Carlsson B, Albertsson- Wikland K. 1997 Increased proportion of circulating non-22-kilodalton growth hormone isoforms in short children: a possible mechanism for growth failure. J Clin Endocrinol Metab. 82:2944-2949.

13. Stanhope R, Preece MA, Hamill G. 1991 Does growth hormone treatment improve final height attainment of children with intrauterine growth retardation? Arch Dis Child. 66:1180-1183.

14. Albanese A, Stanhope R. 1993 Growth and metabolic data following growth hormone treatment of children with intrauterine growth retardation. Horm Res. 39:8-12.

15. Chatelain P, Job JC, Blanchard J, et al. 1994 Dose-dependent catch-up growth after 2 years of growth hormone treatment in intrauterine growth retarded children. J Clin Endocrinol Metab. 78:1454-1460.

16. Job JC, Chaussain JL, Job B, et al. 1996 Follow-up of three years of treatment with growth hormone and of one post-treatment year, in children with severe growth retardation of intrauterine onset. Pediatr Res. 39:354-359.

17. Chaussain JL, Colle M, Landier F. 1994 Effects of growth hormone therapy in prepubertal children with short stature secondary to intrauterine growth retardation. Acta Paediatr Scand. 399(Suppl):74-75.

18. de Zegher F, Maes M, Gargosky SE, et al. 1996 High-dose growth hormone treatment of short children born small for gestational age. J Clin Endocrinol Metab. 81:1887-1892

19. Boguszewski M, Albertsson-Wikland K, Aronsson S. 1998 Growth hormone treatment of short children born small-for-gestational-age: the Nordic Multicentre Trial. Acta Paediatr. 87:257-263.

20. de Zegher F, Butenandt O, Chatelain P, et al. 1997 Growth hormone treatment of short children born small for gestational age: reappraisal of the rate of bone maturation over 2 years and metanalysis of height gain over 4 years. Acta Paediatr Suppl. 423:207-212.

21. Sas T, de Waal W, Mulder P, et al. 1999 Growth hormone treatment in children with short stature born small for gestational age: five-year results of a randomized, double-blind, dose-response trial. J Clin Endocrinol Metab. 84:3064-3070.

22. Barker DJP, Hales CN, Fall CHD, Osmond C, Phipps K, Clark PMS. 1993 Type 2 (non- insulin-dependent) diabetes mellitus, hypertension and hyperlipidaemia (syndrom X): relation to reduced fetal growth. Diabetologia. 36:62-67.

22a.Sas T, Mulder P, Aanstoot HJ, et al. 1999 Carbohydrate metabolism during long-term growth hormone treatment in children with short stature born small for gestational age. Clin Endocrinol. In press.

23. Teunenbroek van A, Muinck Keizer-Schrama de SMPF, Aanstoot HJ, Stijnen T, Hoogerbrugge N, Drop SLS. 1999 Carbohydrate and lipid metabolism during various growth hormone dosing regimens in girls with Turner syndrome. Metabolism. 48:7-14

24. Hokken-Koelega ACS, Stijnen T, de Jong RC, et al. 1996 A placebocontrolled, double- blind trial in prepubertal children after renal transplant. Kidney Int. 49(Suppl 53):S128-S134.

25. Usher R, MacLean F. 1969 Intrauterine growth of liveborn Caucasian infants at sea level: standard obtained from measurements of infants born between 25 and 44 weeks of gestation. J Pediatr. 74:901-910.

26. Roede MJ, Van Wieringen JC. 1985 Growth diagrams 1980, Netherlands. Third nation-wide survey. T Soc Gezondheidsz Suppl. 63:1-34.

27. Tanner JM, Whitehouse R. 1976 Longitudinal standards for height, weightheight, height velocity and stages of puberty. Arch Dis Child. 51:170-179.
28. Cameron N. 1978 The methods of auxological anthropometry. In: Falkner F, Tanner JM, eds. Human growth, ed 2. London: Tindall; 35-87.

29. Gerver WJM, de Bruin R. 1996 Paediatric morphometrics, a reference manual. Utrecht: Bunge.

30. Cole TJ. 1989 The British, American NCHS, and Dutch weight standards compared using the LMS method. Am J Hum Biol. 1:397-408.

31. Cole TJ. 1989 Using the LMS method to measure skewness in the NCHS and Dutch National height standards. Ann Hum Biol. 16:407-419.

32. Task Force on Blood Pressure Control in Children. 1987 Report of the second Task Force on Blood Pressure Control in Children. Pediatrics. 79:1-25.

33. van Stiphout WAHJ, Hofman A, de Bruijn AM, Valkenburg HA. 1985 Distributions and determinants of total and high-density lipoprotein cholesterol in Dutch children and young adults. Prev Med. 14:169-180.

34. Boot AM, Engels MAMJ, Boerma GJM, Krenning EP, de Muinck KeizerSchrama SMPF. 1997 Changes in bone mineral density, body composition, and lipid metabolism during growth hormone $(\mathrm{GH})$ treatment in children with $\mathrm{GH}$ deficiency. J Clin Endocrinol Metab. 82:2423-2428.

35. Gent CM, Voort HA, de Bruijn AM, et al. 1977 Cholesterol determinations. A comparative study of methods with special reference to enzymatic procedures. Clin Chim Acta. 75:243-251.

36. Grove TH. 1979 Effect of reagent $\mathrm{pH}$ on determination of high-density lipoprotein cholesterol by precipitation with sodium phosphotungstatemagnesium. Clin Chim Acta. 25:560-564.

37. Leger I, Carel C, Fjellestad-Paulsen A, Hassan M, Czernichow P. 1998 Human growth hormone treatment of short-stature children born small for gestational age: effect on muscle and adipose tissue mass during a 3-year treatment period and after 1 year's withdrawal. J Clin Endocrinol Metab. 83:3512-3516.

38. Hashimoto N, Kawasaki T, Kikuchi T, Takahashi H, Uchiyama M. 1996 The relationship between the intrauterine environment and blood pressure in 3-year-old Japanese children. Acta Paediatr. 85:132-138.

39. Pharoah POD, Stevenson CJ, West CR. 1998 Association of blood pressure in adolescence with birth weight. Arch Dis Child Fetal Neonatal Ed. 79:F114-F118

40. Yiu V, Buka S, Zurakowski D, McCormick M, Brenner B, Jabs K. 1999 Relationship between birth weight and blood pressure in childhood. Am J Kidney Dis. 33:253-260.

41. López-Velasco R, Escobar-Morreale HF, Vega B, et al. 1997 Cardiac involvement in acromegaly: specific myocardiopathy or consequence of systemic hypertension. J Clin Endocrinol Metab. 82:1047-1053.

42. Barton JS, Hindmarsh PC, Preece MA, Brook CD. 1993 Blood pressure and renin-angiotensin-aldosterone system in children receiving recombinant human growth hormone. Clin Endocrinol. 38:245-251.

43. Frindik JP, Kemp SF, Elders JM, Morris M. 1989 The effect of growth hormone on lipid profiles of growth hormone deficient children. J Pediatr Endocrinol 3:167-170.

44. Blackett PR, Weech PK, McConathy WJ, Fesmire JD. 1982 Growth hormone in the regulation of hyperlipidemia. Metabolism. 31:117-120.

45. Schaefer GB, Greger NG, Fesmire JD, Blackett PR, Wilson DP, Frindik JP. 1994 Lipids and apolipoproteins in growth hormone deficient children during treatment. Metabolism. 43:1457-1461.

46. De Muinck Keizer-Schrama S, Rikken B, Hokken-Koelega A, Wit JM. 1994 Comparative study of two doses of growth hormone for growth hormone deficiency. Arch Dis Child. 71:12-18.

47. Kohno H, Ueyama N, Yanai S, Ukaji K, Honda S. 1994 Beneficial effect of growth hormone on atherogenic risk in children with growth hormone deficiency. J Pediatr. 126:953-955.

48. Kannel WB, Wilson PWF. 1992 Efficacy of lipid profiles in prediction of coronary disease. Am Heart J. 124:768-774.

49. Cowan FJ, Evans WD, Gregory JW. 1999 Metabolic effects of discontinuing growth hormone treatment. Arch Dis Child. 80:517-523. 